\title{
PENDIDIKAN DAN POLITIKUS : ANALISIS PEMIKIRAN M. NATSIR TENTANG PENDIDIKAN ISLAM DI INDONESIA
}

\author{
Ahmad dan Hayati Nufus \\ FITK Institut Agama Islam Negeri (IAIN) Ambon \\ Email : nufushayati119@gmail.com
}

\begin{abstract}
This paper aims to analyze the thoughts of Mohammad Natsir on Islamic Education of Indonesia. Indeed education is a shared responsibility of all people, not just the task of education experts, political experts can play an active role in education. Long before independence and after independence education became the first and foremost thing that must be considered and realized according to the culture and needs of the people of Indonesia. Mohammad Natsir is one of the Indonesian politicians who are able to bring education changes and education curriculum in Indonesia. He no longer sees that public and religious education are separated and unrelated, but integrated. This is evidenced by the existence of educational institutions that he pioneered the Islamic education school and some educational thinking that until now still used in the education curriculum of the Ministry of Religious Affairs of the Republic of Indonesia with the term "integrated education".
\end{abstract}

Keywords: Islamic Education, Thought, Mohammad Natsir

\section{PENDAHULUAN}

Secara umum desain pengembangan kurikulum yang terjadi di sekolah-sekolahdewasa ini lebih banyak menitik beratkan dalam pengembangan ranah pikir atau kognitifsemata. Disusul kemudian yang sedikit mendapat perhatian yaitu pengembangan ranahraga (kinestetik) yang bersifat skill atau psikomotorik. Sementara untuk ranah potensirasa, karsa, dan religi yang menjadi muatan pendidikan moral/karakter dan bersifat afektifkurang mendapat perhatian. Kalaupun ada, untuk ranah rasa, karsa, dan religi ini barudikembangkan sebatas pemenuhan aspek formalitas yang dituangkan dalam RencanaProgram Pembelajaran. (Caroline Damanik dan Hertanto, 2009).

Muhyiddin mengatakan bahwa dalam prakteknya, arah pendidikan nasionalyang sudah berjalan selama ini 95\% menitik beratkan pada unsur kepandaian danintelektual, sedangkan unsur pembangunan moral hanya menjadi pendidikan skunder. Pendidikan yang terjadi dan dilakukan di sekolah masih timpang. Pengembanganranah pikir (kognitif) lebih 
mendapat perhatian dan porsi yang lebih besar, sementararanah rasa, karsa dan religi terabaikan. Terlebih lagi dengan adanya sistem ujian nasionaluntuk beberapa mata pelajaran pada tingkat SD, SMP,dan SMA atau sederajat. Secara tidak sadar, keberadaan ujian nasionaltelah menggiring para peserta didik, guru, atau masyarakat (orang tua) untukmengutamakan olah pikir atau pengembangan intelektualitas (kognitif) semata dalampendidikan. (Al Halaj Muhyiddin, 2012).

Hal ini terjadi karena masih ada dikotomi pemikiran pendidikan umum dan agama, ini jelas terlihat pada lembaga pendidikan yang bersifat umum dan agama, misal ada SD dan MI, SMP dan MTs dan lainnya. Lain lembaga pendidikan maka lain pula kurikulum pendidikannya, sementara tujuanPendidikan Nasional sebagaimana dirumuskan dalam Undangundang Republik Indonesia Nomor 20 Tahun 2003 tentang Sistem PendidikanNasional yang bunyinya sebagai berikut: "Pendidikan nasional berfungsi mengembangkan kemampuan danmembentuk watak serta peradapan bangsa yang bermartabat dalam rangkamencerdaskan kehidupan bangsa, bertujuan untuk berkembangnya potensipeserta didik agar menjadi manusia yang beriman dan bertakwa kepada TuhanYang Maha Esa, berahklak mulia, sehat, berilmu, cakap, kreatif, mandiri, danmenjadi warga negara yang demokratis serta bertanggung jawab". (Departeman Pendidikan dan Kebudayaan, 2005: 94).

Tujuan pendidikan ini mengisyaratkan bahwa pendidikan itu menyeluruh, memperhatikan intelektualitas, sikap dan keterampilan secara bersamaan sehingga menciptakan manusia indonesia yang memiliki kepintaran dan kepribadian yang bermartabat juga memliki keterampilan sesuai bidangnya dan mampu bersaing dengan bangsa lainnya di dunia. Oleh karena itu peningkatan kuantitas peserta didik dan lamanya waktu untuk mengenyam pendidikan formal bukan jaminan mendapatkan hasil-hasil pendidikan yang semestinya, ketika pendidikan itu tidak seimbang proporsinya. Tidak mengherankan perilaku korupsi, 
tawuran, cepat putus asa, egoisme, kurang percaya diri, penyalahgunaannarkotika banyak terjadi pada masyarakat indonesia.

Konsep pendidikan Islam Mohammad Natsir dapat menjadi solusi karena membagi antara pengetahuan umum dan pengetahuan Islam secara seimbang. Mohammad Natsir juga mengatakan, bahwa tak ada satu bangsa yangterbelakang menjadi maju, melainkan sesudahnya mengadakan dan memperbaiki didikan anak-anak dan pemuda-pemuda mereka. (Mohammad Natsir, 1954: 77). Pemuda dan anak-anak merupakan penerus bangsa, maju dan terbelakangnya suatu bangsa tergantung dari seberapa hebat generasi mudanya.

\section{PEMBAHASAN}

\section{Mohammad Natsir}

Mohammad Natsir adalah seorang tokoh politik indonesia yang mulai aktif dibidang politik dengan melibatkan dirisebagai anggota Persatuan Islam Indonesia (PII) cabang Bandung. Pada tahun1940-1942, Natsir menjabat ketua PII, dan pada tahun 1942-1945 merangkap jabatan sebagai Kepala Biro Pendidikan Kota Jakarta yangmerupakan Perguruan Tinggi Islam pertama yang berdiri paska kemerdekaan. (Tim Penyusun IAIN Syarif Hidayatullah, 2002: 844).

Karir politik Natsir pasca kemerdekaan diawali sebagai anggotaKomite Nasional Indonesia Pusat (KNIP), yang berlangsung dari tahun 1945-1946. Kemudian menjadi Menteri Penerangan Republik Indonesia padakabinet Syahrir ke-1 dan ke-2 serta kabinet Hatta ke-1. Dari tahun 1949-1958 ia diangkat menjadi ketua Masyumi, hingga partai ini dibubarkan.Puncak karir Natsir dalam bidang politik terjadi ketika Natsir diangkat sebagaiPerdana Menteri Republik Indonesia (1950-1951). Dalam Pemilihan Umum(Pemilu) 1955 Natsir terpilih menjadi anggota Dewan Perwakilan Rakyat(DPR), dan dari tahun 1956-1957, ia menjadi anggota Konstituante RepublikIndonesia. (Abudin Nata, 2005: 77). Sebagai pemimpin politik Islam, M Natsir telah memberikan seluruhtenaga dan 
fikirannya bagi kepentingan seluruh umat Islam di Indonesia padakhususnya dan pada seluruh rakyat Indonesia pada umumnya. Denganmunculnya pemikiran untuk menyatukan masing-masing Negara bagian untukbersatu kembali dalam Negara kesatuan RI. (Tim Penyusun IAIN Syarif Hidayatullah, 2002: 845).

Mosi Integral disampaikan Mohammad Natsir dalam Sidang Dewan PerwakilanRIS pada tanggal 3 April 1950. Dari mosi integral inilah kemudian lahirproklamasi kedua yang dikumandangkan oleh Presiden Soekarno pada tanggal17 Agustus 1950 di Istana Merdeka, Jakarta. Intinya, RI untuk kedua kalinyadiproklamasikan menjadi Negara kesatuan. Ini berarti pembubaran RIS danpembentukan kabinet baru. Dengan demikian, Mohammad Natsir ditunjuk sebagaipembentuk kabinet karena ia dengan Masyumi mempunyai konsepsi untukmenyelamatkan Republik melalui konstitusi. Mosi integral merupakan debut politik Mohammad Natsir yang amatcemerlang yang sampai sekarang Indonesia menjadi satu dan kokoh. Mosi ini dikenal dengan "Mosi Integral M. Natsir." (Thohir Luth, M, 2005: 48).

Natsir tidak digunakan lagi dalam pemerintahan, bahkan partaiMasyumi yang dipimpinnya dibubarkan karena perbedan pandangan tentanglslam dengan Soekarno, dan juga keinginan Natsir untuk menjadikan Islamsebagai dasar Negara. Pada puncak konflik antara keduanya, Natsir jugamelibatkan diri dalam gerakan oposisi, Pemerintahan Revolusioner RepublikIndonesia (PRRI) di Sumatra. Tokohtokoh ini menyatakan bahwapemerintahan Soekarno telah menyeleweng dari Undang-Undang Dasar 1945,yang mengakibatkan Natsir dan kawankawannya ditangkap dan dimasukkankedalam penjara. (Thohir Luth, M, 2005: 53).

\section{Kontribusi Pemikiran PendidikanMohammad Natsir \\ a. Kurikulum Pendidikan Islam}

Menurut pandangan Mohammad Natsir kurikulum pendidikan dapat disusun dan dikembangkan secara integral dengan mempertimbangkan 
kebutuhan umum dan kebutuhan khusus sesuai dengan potensi yang dimiliki oleh peserta didik, sehingga akan tertanam sikap kemandirian bagi setiap peserta didik dalam menyikapi realitas kehidupannya. Beliau sangat tegas menolak teori dikotomi ilmu yang memisahkan antara ilmu agama dan ilmu umum.Hal ini tentunya sesuai dengan pandangan al-Qur'an tentang manusia. Bahwa manusia adalah makhluk yang memiliki unsur jasmani dan rohani, fisik dan jiwa yang memungkinkan ia diberi pendidikan. Selanjutnya manusia ditugaskan untuk menjadi khalifah muka bumi sebagai pengamalan ibadah kepada Allah dalam arti seluasluasnya.la tidak akan bisa melaksakan tugas ini sebaik-baiknya kecuali dengan penguasaan yang baik terhadap kedua ilmu ini.

Mohammad Natsir juga mengenalkan konsep tauhid sebagai dasar Pendidikan. Tauhid harus menjadi dasar berpijak setiap muslim dalam melakukan segala kegiatannya, diantaranya pendidikan. Mohammad Natsir juga menggariskan bahwa tauhid haruslah dijadikan dasar dalam kehidupan manusia, diantaranya dalam masalah pendidikan.Pendidikan Islam adalah pendidikan yang diasaskan pada tauhid. Beliau berpandangan bahwa pendidikan tauhid harus diberikan kepada anak sedini mungkin, selagi masih muda dan mudah dibentuk, sebelum didahului oleh materi dan ideologi dan pemahaman lain. Supaya ia memiliki tali Allah untuk bergantung. (Lihat Mohammad Natsir, 1954: 115).

Hasil dari pendidikan model ini akan melahirkan generasi-generasi yang memiliki hubungan kuat dengan penciptanya serta mengutamakan mu'amalah sesama makhluk. Dan inilah dua syarat wajib untuk mendapatkan keselamatan dan kebahagiaan hidup, lahir dan batin. Hal ini sesuai dengan firman Allah swt dalam surat Ali Imran:112 


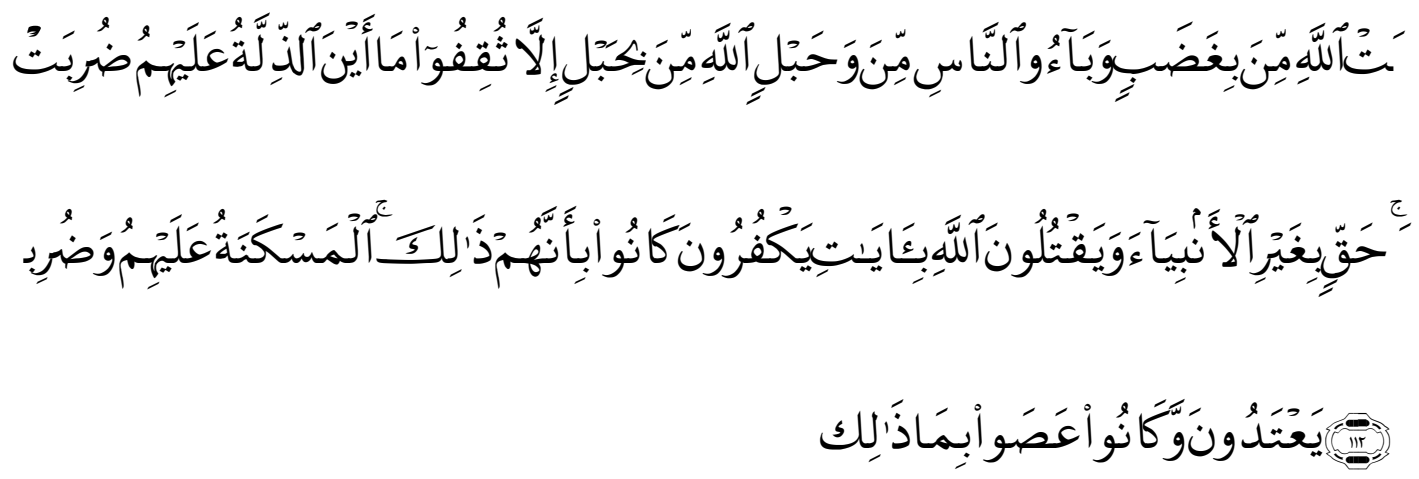

Artinya:

Mereka diliputi kehinaan di mana saja mereka berada, kecuali jika mereka berpegang kepada tali (agama) Allah dan tali (perjanjian) dengan manusia, dan mereka kembali mendapat kemurkaan dari Allah dan mereka diliputi kerendahan.yang demikian itu karena mereka kafir kepada ayat-ayat Allah dan membunuh Para Nabi tanpa alasan yang benar. yang demikian itu disebabkan mereka durhaka dan melampaui batas. (QS. Ali Imran: 112)

Menurut Natsir, meninggalkan dasar tauhid dalam pendidikan anak merupakan kelalaian yang amat besar. Bahayanya, sama besarnya, dengan penghianatan terhadap anak-anak didik. Walaupun sudah dicukupkan makan dan minumnya, pakaian dan perhiasannya, serta dilengkapkan pula ilmu pengetahuan untuk bekal hidupnya.Semua ini, menurutnya, tidak ada artinya apabila meninggalkan dasar ketuhanan (ketauhidan) dalam pendidikan mereka. Natsir memandang bahwa lahirnya para intelektual muslim yang menentang Islam dan kelompok yang western-minded adalah akibat dari pendidikan yang tidak berbasis agama yang benar. Dari sinilah beliau melihat sisi pentingnya tauhid sebagai dasar dari pendidikan Islam.

\section{b. Peranan dan Fungsi Pendidikan}

Terdapat enam rumusan peranan dan fungsi pendidikan menurut Mohammad Natsir, yaitu: 
a. Pendidikan harus berperan sebagai sarana untuk memimpin dan membimbing agar manusia yang dikenakan sasaran pendidikan tersebut dalam mencapai pertumbuhan dan perkembangan jasmani dan rohani secara sempurna.

b. Pendidikan harus diarahkan untuk menjadikan anak didik memiliki sifat-sifat kemanusiaan dan mencapai akhlaqul karimah yang sempurna.

c. Pendidikan harus berperan sebagai sarana untuk menghasilkan manusia yang jujur dan benar.

d. Pendidikan agar berperan membawa manusia agar dapat mencapai tujuan hidupnya, yaitu menjadi hamba Allah SWT.

e. Pendidikan harus dapat menjadikan manusiayang dalam segala perilaku atau interaksi vertikal maupun horizontal selalu menjadi rahmat bagi seluruh alam.

f. Pendidikan harus benar-benar mendorong sifat-sifat kesempurnaan dan bukan sebaliknya, yaitu menghilangkan danmenyesatkan sifatsifat kemanusiaan.

\section{c. Landasan Pendidikan Islam}

Mohammad Natsir memandang bahwa yang harus menjadi landasan pendidikan adalah tauhid. Ini misalnya terlihat pada pidato Natsir dalam rapat Persatuan Islam di Bogor pada tanggal 17 Juni 1934 dengan judul "Ideologi Didikan Islam". Juga terlihat dalam tulisannya di Pedoman Masyarakat pada tahun 1937 dengan judul "Tauhid Sebagai Dasar Didikan" yaitu Mengenalkan Tuhan, mentauhidkan Tuhan, mempercayai dan menyerahkan diri kepada Tuhan, tak dapat tidak harus menjadi dasar bagi tiap-tiap pendidikan yang hendak diberikan kepada generasi yang kita latih, jikalau kita sebagai guru ataupun sebagai ibu bapa, betul-betul cinta kepada anak-anak yang telah dipetaruhkan Allah kepada kita itu. Menurut Mochtar Naim, dalam dua tulisan itu dengan gamblang Natsir 
menggariskan bahwa ideologi pendidikan ummat Islam harus bertitik-tolak dari dan berorientasi kepada Tauhid. (Anwar Harjono, dkk, 2001: 148).

Pentingnya tauhid sebagai dasar pendidikan ini menurut Natsirberhubungan erat dengan akhlak yang mulia.Tauhid dapat terlihatmanifestasinya pada kepribadian yang mulia. Menurut Natsir, jika tauhid dijadikan landasan pendidikan umat Islam maka pendidikan akan membentuk anak didik menjadi:

1. Memiliki kepribadian yang tangguh.

2. Berani mengarungi berbagai kesulitan hidup, bahaya, tipu daya dan bahkan malapetaka.

3. Berani mati demi tegaknya kebenaran dan perintah ilahi.

4. Membentuk keikhlasan, kejujuran dan keberanian serta rasa tanggung jawab untuk melaksanakan suatu tugas atau kewajiban yang diyakini kebenarannya.

Dengan kepribadian seperti diatas, maka seorang anak didik akan menjadi pribadi yang tangguh dalam melaksanakan tugas kemanusiaannya sebagai hamba Allah maupun sebagai mahluk sosial. Maka menurut Natsir tauhid sesungguhnya adalah landasan begi seluruh aspek kehidupan manusia dalam melaksanakan ibadah kepada Allah swt.

\section{d. Tujuan Pendidikan Islam}

Tujuan pendidikan Islam yang ingin dicapai oleh Mohammad Natsir adalah membentuk manusia yang beriman, bertaqwa, berakhlak mulia, maju dan mandiri sehingga memiliki ketahanan rohaniah yang tinggi serta mampu beradaptasi dengan dinamika perkembangan masyarakat. (Abibullah Djaini, 1996: 100). Selain itu bahwa tujuan manusia adalah untuk mendapatkan kebahagiaan hidup di dunia dan di akhirat, tidak akan diperoleh dengan sempurna kecuali dengan keduanya. Pendidikan Islam tidak bisa dipisahkan dari kehidupan manusia. Tujuan pendidikan Islam sama dengan tujuan kehidupan manusia, tujuan ini tercermin dalam al Qur'an Surat Al-An'am: 162. 


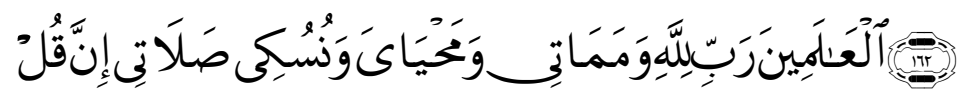

Artinya:

Katakanlah: Sesungguhnya shalatku, ibadahku, hidupku dan matiku hanyalah untuk Allah, Tuhan semesta alam. (Q.S. Al-An'am: 162).

Bagi Mohammad Natsir, fungsi tujuan pendidikan adalah memperhambakan diri kepada Allah SWT semata yang bisa mendatangkan kebahagiaan bagi penyembahnya. Hal ini juga yang disimpulkan oleh Abuddin Nata, tentang tujuan pendidikan Islam menurut Mohammad Natsir, bahwa pendidikan Islam ingin menjadikan manusia yang memperhambakan segenap rohani dan jasmaninya kepada Allah SWT. Hal ini sesuai dengan konsep Islam terhadap manusia itu sendiri.Bahwa mereka diciptakan oleh Allah untuk menghambakan diri hanya kepada Allah semata. Oleh karenanya segala usaha dan upaya manusia harus mengarah ke sana, di antaranya adalah pendidikan.

\section{e. Metode Pendidikan Islam}

Mohammad Natsir telah menempatkan dirinya untuk berada di jalan da'wah.Sehingga apapun yang dijalankan selalu disebatikan dengan misi da'wah. Kecerdasan yang ada pada pada diri beliau dan kuatnya keyakinan terhadap ajaran islam menjadikannya seorang penda'wah yang ulung. Dan kelebihan yang dimilikinya adalah mampu berda'wah dalam berbagai aspek, seperti politik, pendidikan, keilmuan, keperibadian dan tingkah laku.Selain itu objek da'wah yang disentuh tidak hanya untuk kalangan atau golongan tertentu, namun yang menjadi target da'wah adalah mencakup seluruh masyarakat.Baik golongan atas maupun golongan bawah, bahkan kiprahnya dalam da'wah mulai dari daerah, nasional hingga internasional. (Majalah Tempo Edisi 21/XXXVII/14 - 20 Juli 2008: 10). 
Dalam berda'wah di arena politik Pak Natsir terkenal dengan dua kalimat "berda'wah dijalur politik berpolitik dijalur da'wah”. Bagi Pak Natsir berpolitik adalah suatu medan da'wah, sehingga dalam prakteknya harus dilakukan dengan penuh kejujuran, keikhlasan dan sopan santun. Dalam berpolitik sangat tidak pantas kalau hanya menurutkan hawa nafsu dan menepikan hukum Allah.Berpolitik bukan untuk mencari kekuasaan tetapi yang sangat utama adalah mengutamakan kemaslahatan umat.

Mohammad Natsir menukil pendapat Syaikh Mohammad Abduh yang membagi hikmah dalam tiga golongan yaitu:

a. Ada golongan cerdik cendekiawan yang cinta kebenaran, dan dapat berfikir secara kritis, cepat dapat menangkap arti persoalan. Mereka ini harus dipanggil dengan hikmah, yakni dengan alasanalasan, dengan dalil dan hujjah yang dapat diterima oleh kekuasaan akal mereka.

b. Ada golongan awam, orang kebanyakan yang belum dapat berfikir secara kritis dan mendalam, belum dapat menangkap pengertian yang tinggi-tinggi. Mereka ini dipanggil dengan mau'idzah alhasanah, dengan anjuran dan didikan, yang baik-baik, dengan ajaran-ajaran yang mudah difaham.

c. Ada golongan yang tingkat kecerdasannya di antara kedua golongan tersebut, belum dapat dapat dicapai dengan hikmah, akan tetapi tidak sesuai pula, bila dilayani seperti golongan awam; mereka suka membahas sesuatu, tetapi tidak hanya dalam batas yang tertentu, tidak sanggup mendalam benar. Mereka ini dipanggil dengan mujadalah bi al-lati hiya ahsân, yakni dengan bertukar fikiran, guna mendorong supaya berfikir secara sehat, satu dan lainnya dengan cara yang lebih baik. (Saeful Rokhman, 2009).

\section{f. Pendidikan Akhlak}

Akhlak adalah sikap yang terpuji yang harus dimiliki oleh seorangguru. Kemudian ia memerintahkan kepada murid-muridnya 
untukberakhlak baik. Ucapan yang baik, senyuman, dan raut muka yang berseridapat menghilangkan jarak yang membatasi antara seorang guru denganmuridnya. Sikap kasih dan saying, serta kelapangan hati seorang pendidikakan dapat menangani kebodohan seorang murid. (Muhammad Syafii Antoni, 2009: 201).

Sering kali kebanyakan orang meremehkan akan pentingnyapendidikan akhlak, mereka beranggapan bahwa pendidikan akhlak hanya berputar pada kesopanan saja. Padahal jika kita telusuri sangat banyaksekali cabang-cabang yang terdapat dalam pendidikan akhlak. Bahkansaking pentingnya Rasulullah diutus kedunia tidak lain adalah untukmenyempurnakan akhlak manusia.

\section{g. Pendidikan yang bersifat Integral}

Kata integral disini tidak asing lagi bagi kita, sebagaimana Natsirtelah kemukakan dalam "mosi integral Mohammad Natsir", yang manabeliau menginginkan penyatuan wilayah-wilayah yang ada diseluruhIndonesia, tidak membeda-bedakan antara jawa dan luar jawa.Natsir merasa pendidikan Islam tidak layak jika hanya mengetahuitentang mengaji, rukun bersuci dan lain sebagainya yang hanyamengajarkan tentang agama.

Dalam kaitannya dengan pendidikan yang integral natsir seringmengkaitkannya dengan sistem pendidikan barat yang sering dikaitkandengan sistem pendidikan timur, beliau mengatakan: "tidak menjadi soal,apakah itu didikan barat atau didikan timur.Timur kepunyaan Allah, baratpun kepunyaan Allah juga, sebagaimakhluq yang bersifat baru, kedua-duanya, Barat dan Timur, mempunyaihal yang kurang baik dan hal yang baik, mengandung beberapa kelabihandan beberapa keburukan.

\section{h. Lembaga Pendidikan}

Setelah lulus dari AMS pada tahun 1930 dengan nilai memuaskan, Mohammad Natsir berhak mendapat beasiswa sebesar Rp 130 sebulan,kuliah di fakultas hukum diBatavia atau Fakultas Ekonomi di 
Rotterdam, Belanda. Namun dengan pertimbangan yang sangat matang, Mohammad Natsir kemudian memutuskan untuk tidak mengambil kesempatan itu.la memilih untuk terus belajar kepada Ahmad Hassan dan setelah berdiskusi dengan Hassan, Mohammad Natsir merintis sebuah sekolah kecil di Jalan Lengkong Besar Nomor 16 yang kemudian dikenal dengan namaSekolah Pendidikan Islam (Pendis). (Ajib Rosyidi, 1990: 165) Mohammad Natsir mendirikan Pendis saat usianya masih sangat muda yaitu 23 tahun dan menjadi pelopor Pendidikan Integral saat itu.

Pendis adalah sebuah sekolah partikelir dengan sistem pendidikan integral.Apa yang dilakukan Natsir dengan Pendis ini menjadi penting karena beberapa hal. Pertama, secara konsisten Mohammad Natsir menerapkan visi pendidikannya dalam kurikulum pengajaran dalam bentuk yang integral.Mohammad Natsir menempatkan pelajaran-pelajaran dasar agama sejajar dengan pelajaran-pelajaran lainnya.Kedua,Mohammad Natsir tidak menempatkan Pendis sebagai satu-satunya model pendidikan yang harus dikembangkan.

Secara konsisten Mohammad Natsir juga menyokong berdirinya Pesantren Persatuan Islam (Persis) pada tahun 1936 atas inisiatif Ahmad Hassan.MohammadNatsir ikut merumuskan kurikulum dan menjadi pengajar di sini. Sesuai dengan visinya, pesantren yang baru berdiri itu tidak hanya mengajarkan disiplin ilmu agama secara mendalam, tapi juga memperkenalkan pengetahuan-pengetahuan umum seperti pengetahuan sosial, Bahasa Belanda, Bahasa Inggris, Ilmu Mengajar, dan sedikit ilmuilmu Alam. Ketiga, visi dan prinsip yang dipegang Mohammad Natsir ini, terus dipegang sepanjang hayatnya nanti, dalam posisi apapun.

Selain mendirikan Pendis Mohammad Natsir juga tercatat ikut mendirikan sembilan universitas di berbagai kota di Indonesia. Diantaranya adalah Ibn Khaldun Bogor, UISU Medan, UNISBA Bandung, UMI Makassar, UNISSULA Semarang, UIR Riau dan Universitas al-Azhar Indonesia Jakarta. Konstribusi Mohammad Natsir dalam berdirinya sembilan universitas adalah sebagai pemberi rekomendasi dan konsultan 
dalam memperlancar urusan administrasi berdirinya kesembilan universitas tersebut.

\section{PENUTUP}

Konsep Pendidikan Islam yang diterapkan Mohammad Natsir adalah pendidikan yang harus dapat membawa manusia mencapai tujuan hidupnya, yaitu menghambakan diri kepada Allah, berakhlak al- karimah dan mendapat kehidupan yang layak di dunia. Selain itu pendidikan Islam haruslah bersifat integral tanpa memisahkan dan membedakan pengetahuan umum dan pengetahun agama, ilmu yang berasal dari Barat dan Timur sehingga tidak terjadi dikotomi ilmu. Konstribusi yang diberikan Mohammad Natsir bagi dunia pendidikan Indonesia yaitu sebagai pelopor berdirinya lembaga Pendidikan Islam pertama di Indonesia yang bersifat modern dengan sistem pendidikan yang berintegrasi. Sedangkan dalam dunia politik Mohammad Natsir sebagai salah satu pendiri partai Islam terbesar pada masa orde lama sebagai manifestasi dari tekad semua umat Islam pada saat itu.

\section{DAFTAR PUSTAKA}

[1] Al Halaj Muhyiddin, 2012, Meluruskan Arah Pendidikan Nasional. http://alkautsar.com. diakses: 3 Juni 2012.

[2] Antoni, Muhammad Syafii. 2009, Muhammad Saw The Super Leader Super Manager, Jakarta: ProLM dan Tazkia Publishing.

[3] Caroline Damanik dan Hertanto, 2009, KemanaArahpendidikanNasional, Kompas.com. http://edukasi.kompas.com diakses: 18 Agustus 2015.

[4] Departeman Pendidikan dan Kebudayaan, 1989, Undang-undang Nomer 20 Tahun 2003 tentang system pendidikan Nasional Beserta Penjelasannya, Jakarta: Balai Pustaka.

[5] Departemen Agama RI, 2010, Al-Qur'an dan Terjemahan, Bandung: Mizan Press. 
[6] Djaini, Abibullah. 1996, Pemikiran dan Perjuangan Mohammad Natsir, Jakarta: Pustaka Firdaus.

[7] Harjono,Anwar, dkk, 2001, Pemikiran dan Perjuangan Mohammad Natsir, Jakarta: Pustaka Firdaus.

[8] Jurnal Pemikiran Agama dan Peradaban/TANWIR, Perjalanan Politik Muhammadiyah dari ahmad Dahlan hingga Syafi'i Ma'arif, edisi Perdana, Vol. 1, mei 2003.

[9] http://digilib.umm.ac.id /gdl.php/Pemikiran Pendidikan Islam Muhammad Natsir

[10] Luth, Thohir. 1999, M. Natsir Dakwah dan Pemikirannya, Jakarta: Gema Insani Press.

[11] Majalah Tempo, Edisi 21/XXXVII/14 - 20 Juli 2008.

[12] Mangkusasmito,Prawoto,1951, Memperingati enam tahun Masyumi, Jakarta: PT. Hikmah.

[13] Nata, Abudin. 2005, Tokoh-Tokoh Pembaruan Pendidikan Islam di Indonesia, Jakarta: PT Raja Grafindo Persada.

[14] Natsir, M. 1954, Capita Selekta, Jakarta: Bulan Bintang. 1988, Islam dan Akal Merdeka, Jakarta: Media Da'wah.

[16] Rosyidi, Ajib, 1990, M Natsir Sebuah Biografi, Jakarta: Girimukti Pasaka.

[17] Samsuri, 2004, Politik Islam Anti Komunis, Jogjakarta: PT. Safira Insani Press.

[18] Syafri,Ulil Amri,Pemikiran Pendidikan Natsir Parade yang Belum Usai; Majalah Al-Mujtama'; edisi 3 Th I/14 Rajab 1429/17 Juli 2008

[19] Tamam,Badru,Konsep Pendidikan Mohammad Natsir. http://www.voa-islam.com/teenage print/ 2009/07/09/187 /konseppendidikan-mohammad-natsir. diakses: 18 Agustus 2015.

[20] Tim Penyusun IAIN Syarif Hidayatullah, 2002, Ensiklopedia Islam Indonesia, Jakarta: Djambatan. 